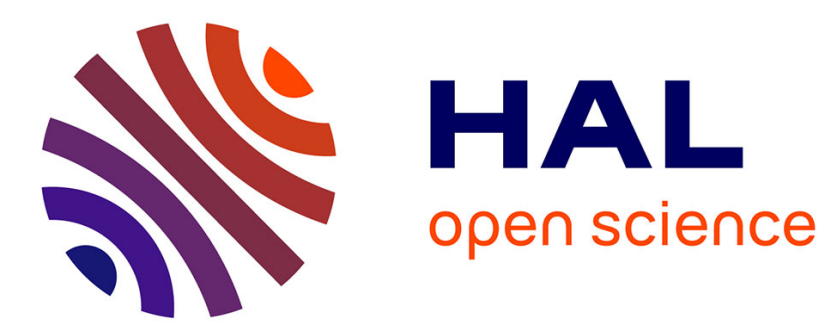

\title{
Promises of the "Nano-World" for electrochemical sensing and energy devices
}

\author{
Alain Walcarius
}

\section{To cite this version:}

Alain Walcarius. Promises of the "Nano-World" for electrochemical sensing and energy devices. Journal of Solid State Electrochemistry, 2020, 24 (9), pp.2189-2191. 10.1007/s10008-020-04684-1 . hal02981485

\section{HAL Id: hal-02981485 \\ https://hal.univ-lorraine.fr/hal-02981485}

Submitted on 28 Oct 2020

HAL is a multi-disciplinary open access archive for the deposit and dissemination of scientific research documents, whether they are published or not. The documents may come from teaching and research institutions in France or abroad, or from public or private research centers.
L'archive ouverte pluridisciplinaire HAL, est destinée au dépôt et à la diffusion de documents scientifiques de niveau recherche, publiés ou non, émanant des établissements d'enseignement et de recherche français ou étrangers, des laboratoires publics ou privés. 


\title{
Promises of the "Nano-World" for Electrochemical Sensing and Energy Devices
}

\author{
Alain Walcarius* \\ Université de Lorraine, CNRS, LCPME, F-54000 Nancy, France \\ *E-mail: alain.walcarius@univ-lorraine.fr; address: Laboratoire de Chimie Physique et \\ Microbiologie pour les Matériaux et l'Environnement (LCPME), UMR 7564 CNRS-Université de \\ Lorraine, 405 rue de Vandoeuvre, 54600 Villers-lès-Nancy, France.
}

\section{Introduction}

Does talking about nano to a chemist make sense? Indeed, chemists are "playing" with very small objects (i.e., molecules) for as long as chemistry exists. But it is clear that the "NanoWorld" has revolutionized many areas of Chemistry, among them electrochemistry. The reasons are not so much that small is beautiful or the need for miniaturization, but rather that the properties of an object can be intrinsically different when its size becomes smaller than a critical dimension or when its structure/morphology can be tuned at the nanoscale. One can clearly understand that reducing (or increasing) the size by a factor ten in one dimension will contribute to decrease (or enlarge) areas and volumes by a factor of a hundred or a thousand, respectively, with the associated dramatic variations in terms of surface boundary effects or surface-to-volume ratios. Similarly, when introducing a porosity at the nanometre scale (or below) in a solid object, this may not only increase its specific surface area by several orders of magnitude but also modify its intrinsic reactivity compared to a bulk material of the same composition. One example illustrative of the first concept is that of ultramicroelectrodes ( $\mu \mathrm{m}$ size or less), which were first designed to local measurements in the human body but have been much more largely used afterwards owing to their unconventional properties, making them likely to be used in poorly conductive media or to enable analytical investigations in the nanosecond time scale, which is not possible with electrodes of conventional size ( $\mathrm{mm}$ size) [1]. Another example to illustrate the second concept is that of nanostructured electrode 
materials, which are characterized by ultrahigh density of active sites while maintaining a high level of accessibility for effective mass transport, and therefore very attractive for applications in the field of electrochemical sensing or energy storage and conversion, for instance [2-5]. A third aspect, actually featured by both families of nanomaterials (nanoparticles and nanostructured solids), is related to their electrocatalytic properties induced by their small size and/or structuration at the nanoscale [6]; such catalytic features can accelerate charge transfer reactions and thereby offer benefits to current and future technologies with social relevance where electrochemistry is involved and for which the basic foundations are similar $[2,7-9]$. Many things have been already made in these directions but, scientifically-peaking, there is still a lot of questions to be answered and many developments calling electrochemists. I'll try to consider very briefly some aspects of two topics in the next paragraphs: sensing and energy, two domains in which electrochemists have great role to play nowadays.

\section{Electrochemical sensing}

Electrochemical sensors are a sub-class of chemical sensors that are basically interesting for low-cost, on-site quantification purposes and real-time monitoring, compared to other analytical techniques requiring more sophisticated facilities associated to sample preparation procedures (which are often not simple enough for point-of-care applications). Their ability to determine the concentration of target species, either directly (heavy metals or pesticides, for instance) or indirectly (redox-inactive species involved in biological reactions that can be detected via an electrochemical transduction), makes them promising but at the condition to be sensitive and selective enough and offering an acceptable long-term operational stability. If the glucose sensors and some other electrochemical biosensors are now established among the commercially successful technologies [10-12] and if wearable and/or skin electrochemical sensors appear to be very promising for economically viable applications [13-15], there are 
still a lot of room for improvement. Nanomaterials have proven to be suitable candidates contributing to the evolvement of electrochemical sensing platforms and hundreds of reviews are available dealing with the use of various kinds of electrode modifiers, such as nanoparticles, 2D layered nanomaterials or 3D nanostructures owing to their electrocatalytic response and/or recognition capabilities (see some illustrative examples [16-21]). However, the focus of many studies is targeted towards feasibility demonstration, association of multiple nanomaterials for signal amplification, determination of analytical figures of merit and comparing systems between them, etc. but not always with a good knowledge of the associated mechanisms and the objective of real sample analyses (i.e., not intentionally spiked media). Some key issues that are ripe for investigation are: the distinction between real synergistic effects and 'simple' additive contributions in case of using multiple nanocomponents; the elucidation of signal amplification mechanisms, notably with respect to the question of selectivity (e.g., what about the interest of using an electrocatalyst that is active for several species, including possible interference?); an integrative approach might be useful to determine the most adequate electrode modifier(s) for a target analyte (perhaps data mining could help on that matter, providing the analytical procedures and results can be compared); the optimal design of an electrode material exhibiting mass and electron transfer processes as fast as possible (which probably needs to be associated to an effective recognition element to ensure proper selectivity of the sensitive detection); smart sensors based on miniaturized multi-electrodes (lab on chip) associated to artificial intelligence for improving selectivity by cross-talking; or determining the electrochemical behaviour of recently discovered nanomaterials (e.g., non-carbonaceous 2D or 3D materials). This will require more fundamental understanding of both the amplification strategies and the physico-chemical properties of such electrode modifiers [22], as wall as suitable 
nanoengineering design to build electrochemical sensing devices for environmental or health issues monitoring, which one may hope to be suitably addressed from closer collaborations between materials scientists and electrochemists.

\section{Energy devices}

A domain where such close collaboration is perhaps more straightforward is that or energy conversion and storage, probably for historical reasons, which is notably illustrated through the Nobel Prize in Chemistry 2019 for the development of lithium-ion batteries. Indeed, nanomaterials, and especially nanostructured materials, are at the centre of most electrochemistry-related technologies pertaining to energy and, again, hundreds of reviews are available dealing with the attractiveness of the "Nano-World" in developing batteries, capacitors, fuel cells, solar cells or other electrochemical energy-harvesting systems (see some illustrative examples [23-29]). Optimization of existing technologies and finding of new energy-generation/conversion and storage solutions will certainly require that the researches in support of electrochemistry application in energy should be oriented towards the elucidation of its fundamental aspects. Good practices to evaluate and compare the performance of such devices are also necessary [30]. A sub-domain for which fundamental electrochemical investigations have been particularly useful is that of capacitors, notably via the insightful elucidation of electrical double layer energy storage with microporous carbon electrodes [31]. Just to keep focusing on one aspect of this very wide area of research, a domain where nanoscience and nanotechnology are expected to play a major role in near future is that of supercapacitors, which are energy storage devices with both high energy and power density [32-35]. The search for new materials likely to increase the energy density of classical electrochemical capacitors (i.e., based on double layer charge/discharge processes) led to the emergence of so-called supercapacitors involving pseudocapacitive materials [36] 
in which a faradic contribution is added to the conventional capacitive behaviour (the word "pseudocapacitive" is used here even if the border between supercapacitors and batteries is still a matter of debate from the terminological point of view $[37,38])$. What needs to be done in this case is the design and development of composite materials containing the necessary constituents ensuring a large charge storage capacity along with fast electron transfer rates. This could be ideally obtained from large area conducting supports (as multi-dimensional carbon nanostructures or more recent two-dimensional materials) carefully modified with thin layers of faradic compounds. Nowadays, such layers are mainly metal monolayers generated by underpotential deposition or insertion/intercalation coatings usually used in batteries but suffering therefore from slow reaction rates (both in terms of electron transfer kinetics or diffusional limitations). Strategies are thus to be found to get large area electrodes uniformly coated with thin films displaying a huge contribution of efficient self-exchangebased charge transfer and fast coupled mass transport $[39,40]$. A possible avenue would be the molecular engineering of rigid nanostructures with redox sites anchored via flexible arms to enable high electron transfer rates between adjacent electroactive centers whereas the open rigid framework ensures rapid diffusion of counter ions.

\section{Conclusion}

Through these two sub-fields of electrochemical science, it is clear that combining the "NanoWorld" with electrochemistry has contributed, is still contributing, and will contribute in the future to the development of emerging technologies useful to the human being. Electrochemistry, as well as nanoscience and nanotechnology, are in their golden age. Nevertheless, despite the abundance of research funds for applied scientific research, much work has still to be performed in building the fundamentals of these areas, and this is not incompatible as one learned from many successful stories in the past. Moreover, 
independently on the target applications, the same basics of electrochemistry can be useful in several fields which may appear distant from each other (e.g., similar concepts of electrocatalysis are likely to be exploited in bioelectrochemistry, electrochemical sensing or energy). Hoping it can inspire the younger generation for the future, without forgetting that most glaring discoveries and breakthroughs originate from very simple ideas.

\section{Acknowledgements}

The author is grateful to Professor Dr. Fritz Scholz for his kind invitation to write such a small contribution to the special issue entitled "Future tasks of electrochemical research".

\section{References}

[1] Amatore C (1993) In: Pombeiro AJL, McCleverty JA (eds) Molecular electrochemistry of inorganic, bioinorganic and organometallic compounds. NATO ASI Series (Serie C: Mathematical and Physical Sciences), vol 385. Springer, Dordrecht.

[2] Walcarius A (2013) Chem Soc Rev 42:4098-4140

[3] Moldoveanu I, van Stefan-Staden RI, van Staden JF (2015) In: Aliofkhazraei M, Makhlouf A (eds) Handbook of Nanoelectrochemistry. Springer, Cham

[4] Manthiram A, Vadivel Murugan A, Sarkar A, Muraliganth (2008) Energy Environ Sci 1:621-638

[5] Sun H, Zhu J, Baumann D, Peng L, Xu Y, Shakir I, Huang Y, Duan X (2019) Nat Rev Mater $4: 45-60$

[6] Garlyyev B, Fichtner J, Pique O, Schneider O, Bandarenka AS, Calle-Vallejo F (2019) Chem Sci 10:8060-8075

[7] Jin H, Guo C, Liu X, Liu J, Vasileff A, Jiao Y, Zheng Y, Qiao SZ (2018) Chem Rev 118:6337-6408 
[8] Walcarius A (2017) Sensors 17:1863/1-1863/42

[9] Xu W, Wu Z, Tao S (2016) J Mater Chem A 4:16272-16287

[10] Wang J (2008) Chem Rev 108:814-825

[11] Heller A, Feldman B (2008) Chem Rev 108:2482-2505

[12] Turner APF (2013) Chem Soc Rev 42:3184-3196

[13] Kim J, Kumar R, Bandodkar AJ, Wang J (2017) Adv Electron Mater 3:1600260

[14] Hubble LJ, Wang J (2019) Electroanalysis 31:428-436

[15] Ferreira PC, Ataide V, Silva Chagas CL, Angnes L, Tomazelli Coltro WK, Longo Cesar Paixao TR, Reis de Araujo W (2019) Trends Anal Chem 119:115622

[16] Sehit E, Altintas Z (2020) Biosensors Bioelectron 159:112165

[17] Li M, Chen T, Gooding JJ, Liu J (2019) ACS Sensors 4:1732-1748

[18] Alarcon-Angeles G, Palomar-Pardave M, Merkoci A (2018) Electroanalysis 30:12711280

[19] Zhu C, Du D, Eychmuller A, Lin Y (2015) Chem Rev 115:8896-8943

[20] Yao S, Ren P, Song R, Liu Y, Huang Q, Dong J, O'Connor BT, Zhu Y (2020) Adv Mater $32: 1902343$

[21] Chen A, Chatterjee S (2013) Chem Soc Rev 42:5425-5438

[22] Gan X, Zhao H (2019) Curr Opin Electrochem 17:56-64

[23] Simon P, Tarascon JM (2013) In: Garcia-Martinez J (ed) Nanotechnology for the Energy Challenge, Second Edition. Wiley-VCH Verlag GmbH \& Co. KGaA, Chap 10, pp 277-298

[24] Gogotsi Y (2014) ACS Nano 8:5369-5371 
[25] Trogadas P, Ramani V, Strasser P, Fuller TF, Coppens MO (2016) Angew Chem Int Ed $55: 122-148$

[26] Zhao F, Bae J, Zhou X, Guo Y, Yu G (2018) Adv Mater 30:1801796

[27] Yun Q, Lu Q, Zhang X, Tan C, Zhang H (2018) Angew Chem Int Ed 57:626-646

[28] Pomerantseva E, Bonaccorso F, Feng X, Cui Y, Gogotsi Y (2019) Science 366:eaan8285

[29] Zhou G, Xu L, Hu G, Mai L, Cui Y (2019) Chem Rev 119:11042-11109

[30] Mathis TS, Kurra N, Wang X, Pinto D, Simon P, Gogotsi Y (2019) Adv Energy Mater 9:1902007

[31] Simon P, Gogotsi Y (2013) Acc Chem Res 46:1094-1103

[32] Yan J, Li S, Lan B, Wu Y, Lee PS (2020) 30: 1902564

[33] Bhoyate S, Kahol PK, Gupta RK (2019) Nanoscience 5:1-29

[34] Huang L, Santiago D, Loyselle P, Dai L (2018) Small 14:1800879

[35] Simon P, Gogotsi Y (2008) Nat Mater 7:845-854

[36] Wang J, Dong S, Ding B Wang Y, Hao X, Dou H, Xia Y, Zhang X (2017) Natl Sci Rev 4:7190

[37] Simon P, Gogotsi Y, Bruce D (2014) Science 343:1210-1211

[38] Brousse T, Bélanger D, Long JW (2015) J Electrochem Soc 162:A5185-A5189

[39] Sk MM, Yue CY, Ghosh K, Jena RK (2016) J Power Sources 308:121-140

[40] Yu M, Feng X (2019) Joule 3:338-360 